Supporting Information (Experimental Methods and Supplementary Data)

\title{
Fluorometric Detection of MicroRNA using Isothermal Gene Amplification and Graphene Oxide
}

Chaesun Hong, ${ }^{a}$ Ahruem Baek, ${ }^{a}$ Sang Soo Hah, ${ }^{\mathrm{b}}$ Woong Jung, ${ }^{\mathrm{c}}$ Dong-Eun Kim ${ }^{*}, \mathrm{a}$

${ }^{a}$ Department of Bioscience and Biotechnology, Konkuk University, Seoul 143-701,Korea

${ }^{b}$ Department of Chemistry and ${ }^{c}$ Department of Emergency Medicine, Kyung Hee University, Seoul 130-701, Korea

*Corresponding author; E-mail: kimde@konkuk.ac.kr 


\section{Experimental Methods}

\section{Oligonucleotides}

The RNA oligonucleotides used in this study (miRNA21, miRNA16, miRNA31, and miRNA155; sequences are shown in Table S1) were chemically synthesized (ST Pharm Co. Ltd., Seoul, Korea) and purified by HPLC and polyacrylamide gel electrophoresis (PAGE). The DNA oligonucleotides (RCT21, RCT16, RCT31, and RCT155; sequences are shown in Table S1) and fluorescently labeled peptide nucleic acids (PNA21, PNA16, PNA31, and PNA155; sequences are shown in Table S1) were chemically synthesized (Bionics, Seoul, Korea and PANAGENE, Daejeon, Korea, respectively) and further purified by PAGE.

\section{Graphene oxide (GO) and atomic force microscopy (AFM)}

Graphene oxide (GO) that was prepared by Hummer's method was purchased from the vendor (cat\#. SKU-HCGO-W-175, Graphene Supermarket, Graphene Laboratories, Inc., Ronkonkoma, NY, USA). The AFM images were collected using an atomic force microscope with a NanoScope V controller (Model: Bruker Multimode 8, Bruker AXS Inc., Madison, WI, USA) at room temperature in tapping mode with spring constant of $40 \mathrm{~N} / \mathrm{m}$ and tip radius of $\leq 8 \mathrm{~nm}$.

$10 \mu \mathrm{L}$ of the graphene oxide solution $(10 \mu \mathrm{g} / \mathrm{mL})$ was used and then was placed on freshly cleaned silicon wafer washed by the piranha cleaning method. The sample was dried at room temperature. The scanning speed was at a line frequency of $1.0 \mathrm{~Hz}$, and the original images were sampled at are solution of $256 \times 256$ pixels.

\section{Circularization of rolling circle template (RCT) DNA}

The ligation reaction of the rolling circle template (RCT) DNA was performed in $10 \mu \mathrm{L}$ of 
reaction mixture containing $1 \mu \mathrm{L}$ of $10 \times$ ligation buffer $(660 \mathrm{mM}$ Tris- $\mathrm{HCl}, \mathrm{pH} 7.6,66 \mathrm{mM}$

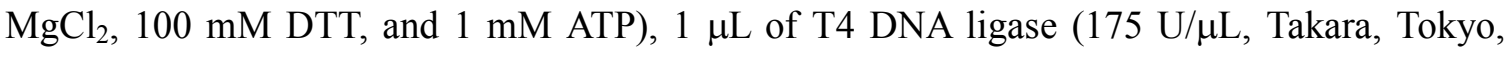
Japan), $1 \mu \mathrm{L}$ of RCT DNA $(1 \mu \mathrm{M}), 1 \mu \mathrm{L}$ of miRNA $(1 \mu \mathrm{M})$ and $6 \mu \mathrm{L}$ of distilled water. Before the T4 DNA ligase and the ligation buffer were added, the RCT and miRNA were heated at $85^{\circ} \mathrm{C}$ for $3 \mathrm{~min}$, and then slowly cooled to room temperature for $15 \mathrm{~min}$. After adding the $\mathrm{T} 4$ DNA ligase and ligation buffer, the reaction mixture was incubated at $25^{\circ} \mathrm{C}$ for $1 \mathrm{~h}$. Then, 10 $\mu \mathrm{L}$ of the ligation reaction mixture was supplemented with a solution containing $2 \mathrm{U}$ of Exonuclease I (2 U/ $\mu \mathrm{L}$, New England Biolabs, Ipswich, MA, USA), $1.5 \mu \mathrm{L}$ of $10 \times$ Exonuclease I reaction buffer $(670 \mathrm{mM}$ glycine- $\mathrm{KOH}, \mathrm{pH} 9.5,100 \mathrm{mM} \beta$-mercaptoethanol, and $67 \mathrm{mM} \mathrm{MgCl} 2$ ), and distilled water in a total volume of $15 \mu \mathrm{L}$. After further incubation at $37^{\circ} \mathrm{C}$ for $15 \mathrm{~min}$, the reaction was quenched by adding an equal volume of the gel-loading dye containing $25 \mathrm{mM} \mathrm{NA}_{2}$ EDTA and $8 \mathrm{M}$ urea. The reaction products were resolved by $15 \%(\mathrm{w} / \mathrm{v})$ denaturing PAGE and the product bands were visualized with SYBR Gold (Molecular Probes, Life Technologies, Eugene, OR, USA).

\section{Rolling circle amplification (RCA)}

The RCT ligation reaction was performed in a $10 \mu \mathrm{L}$ of reaction mixture containing ligation buffer, T4 DNA ligase, and the respective RCT21 (100 nM) and miRNA (designated concentration). Before T4 DNA ligase and ligation buffer were added, the RCT DNA and miRNA samples were heated at $85^{\circ} \mathrm{C}$ for 3 min and then slowly cooled to room temperature for $15 \mathrm{~min}$. After the ligation reaction mixture had been incubated at $25^{\circ} \mathrm{C}$ for $1 \mathrm{~h}, 10 \mu \mathrm{L}$ of rolling circle amplification (RCA) mixture containing $2 \mu \mathrm{L}$ of $10 \times$ RCA reaction buffer ( $500 \mathrm{mM}$ Tris$\mathrm{HCl}, \mathrm{pH} 7.5,100 \mathrm{mM} \mathrm{MgCl}_{2}, 100 \mathrm{mM}\left(\mathrm{NH}_{4}\right)_{2} \mathrm{SO}_{4}$, and $40 \mathrm{mM}$ DTT $), 1 \mu \mathrm{L}$ of BSA $(2 \mathrm{mg} / \mathrm{mL})$, $6 \mu \mathrm{L}$ of dNTP mix $(2.5 \mathrm{mM}$ each $\mathrm{dNTP})$, and $1 \mu \mathrm{L}$ of phi29 DNA polymerase $(5 \mathrm{U} / \mu \mathrm{L}$, New 
England Biolabs) was prepared and mixed with the $10 \mu \mathrm{L}$ of the ligation reaction mixture (total volume $20 \mu \mathrm{L}$ ). The RCA reactions were performed at $30^{\circ} \mathrm{C}$ for $90 \mathrm{~min}$ and terminated by heating at $65^{\circ} \mathrm{C}$ for $10 \mathrm{~min}$. The RCA products (RCAPs) were analyzed with $1 \%$ agarose gel electrophoresis, and the DNA bands were visualized with ethidium bromide.

\section{Spectrofluorometric analysis of fluorescence quenching by GO}

$50 \mu \mathrm{L}$ of reaction solution containing $5 \mu \mathrm{L}$ of fluorescently labeled PNA (F-PNA; $1 \mu \mathrm{M}$ ), $5 \mu \mathrm{L}$ of $10 \times \mathrm{GO}$ binding buffer $\left(50 \mathrm{mM} \mathrm{MgCl}_{2}\right.$ and $200 \mathrm{mM}$ Tris-HCl, $\left.\mathrm{pH} 7.5\right)$ and $40 \mu \mathrm{L}$ of distilled water was prepared and mixed. The emission fluorescence spectrum of the reaction solution was measured in the wavelength range of 500-600 nm upon excitation at $495 \mathrm{~nm}$, using a spectrofluorophotometer (Model RF-53-1PC; Shimadzu Inc., Kyoto, Japan). The emission spectrum change was scanned after GO $(10 \mu \mathrm{g} / \mathrm{mL})$ was added to a reaction solution containing F-PNA (100 nM) and GO binding buffer. To validate the specificity of the GObased fluorometric miRNA detection method, ligation and RCA reaction were conducted (as described above) in a reaction mixture containing miRNA(100 nM) and RCT (100 nM). Long stretches of single-stranded DNA (RCAP21 and RCAP16) were resulted from RCA of miRNA21 and miRNA16, respectively. As a negative control, the same ligation and RCA reaction were performed with RCT21 $(100 \mathrm{nM})$ in the absence of target miRNA21. Each respective RCAP reaction mixture $(3 \mu \mathrm{L}), 5 \mu \mathrm{L}$ of F-PNA21 $(1 \mu \mathrm{M})$, and $7 \mu \mathrm{L}$ of distilled water were hybridized by first heating at $85^{\circ} \mathrm{C}$ for $3 \mathrm{~min}$ and then slowly cooling to room temperature for $15 \mathrm{~min}$. Each RCAP/F-PNA hybrid reaction mixture $(15 \mu \mathrm{L})$ was then supplemented with a solution containing $10 \mu \mathrm{L}$ of GO $(50 \mu \mathrm{g} / \mathrm{mL})$ dissolved in $5 \mu \mathrm{L}$ of $10 \times$ GO binding buffer and $20 \mu \mathrm{L}$ of distilled water (a total volume of $50 \mu \mathrm{L}$ ). After further incubation at $25^{\circ} \mathrm{C}$ for $20 \mathrm{~min}$, the emission spectrum of the mixture $(50 \mu \mathrm{L})$ was measured in 
the wavelength range of 500-600 nm upon excitation at $495 \mathrm{~nm}$, using a spectrofluorophotometer (Model RF-5301PC) (Figure 1c).

\section{Optimization of GO concentration for probe PNA fluorescence quenching}

Ligation and RCA reaction were conducted in a reaction mixture containing miRNA (10 $\mathrm{nM})$ and RCT (100 nM), as described above. The synthesized RCAPs were then subjected to F-PNA (100 nM) hybridization. A $15 \mu \mathrm{L}$ of the RCAP/F-PNA hybrid reaction mixture was then transferred to each well containing $35 \mu \mathrm{L}$ of GO solution at various concentrations $(0,3,5,10$, 20, 30, and $50 \mu \mathrm{g} / \mathrm{mL}$, final concentration), GO binding buffer (20 mM Tris- $\mathrm{HCl}, \mathrm{pH} 7.5,5$ $\mathrm{mM} \mathrm{MgCl} 2$ ), and distilled water in the 96-well plate. After incubation at $25^{\circ} \mathrm{C}$ for $20 \mathrm{~min}$, the fluorescence was measured with a multilabel plate reader (VICTOR X3; PerkinElmer, Waltham, MA, USA) at an excitation wavelength of $485 \mathrm{~nm}$ and an emission wavelength of $535 \mathrm{~nm}$.

\section{Fluorescence measurement with different concentrations of miRNA}

To assess the sensitivity of the GO-based miRNA detection system, the ligation reaction with RCT21 (100 nM) and increasing concentrations of miRNA21 $(0,1,5,100$, and $500 \mathrm{fM} ; 1,50$, 100, and $500 \mathrm{pM} ; 1,5$, and $10 \mathrm{nM}$ ) was performed as described above (Figure 2). The sensitivity of the GO-based miRNA detection method was also examined by performing the same reaction with RCT21 (100 nM) and increasing concentrations of miRNA ( 0 and $5 \mathrm{fM} ; 0.1$, 5, 50, and $500 \mathrm{pM} ; 5,10,50$, and $100 \mathrm{nM})$ mixed in total cellular RNA $(1 \mu \mathrm{g})$, as described above (Figure S3). Total cellular RNA was extracted from lysed lung cancer cells (A549 cells) using TRIzol ${ }^{\circledR}$ solution (Invitrogen, Carlsbad, CA, USA). Ligation and RCA reactions were conducted and the RCAP mixture was subject to F-PNA (100 nM) hybridization as described above. The RCAP/F-PNA hybrid reaction mixture $(15 \mu \mathrm{L})$ was supplemented with a solution 
containing $5 \mu \mathrm{L}$ of $\mathrm{GO}(50 \mu \mathrm{g} / \mathrm{mL}), 5 \mu \mathrm{L}$ of $10 \times \mathrm{GO}$ binding buffer and $25 \mu \mathrm{L}$ of distilled water in a total volume of $50 \mu \mathrm{L}$. After further incubation at $25^{\circ} \mathrm{C}$ for $20 \mathrm{~min}$, the emission spectrum of the mixture $(50 \mu \mathrm{L})$ was scanned by spectrofluorophotometer (Model RF-5301PC) upon excitation at $495 \mathrm{~nm}$.

\section{Quantitative real-time PCR (qRT-PCR) for miRNA detection}

For detection of miRNA21, stem-loop RT-PCR was performed as previously described. ${ }^{1}$ Reverse transcription (RT) and quantitative real-time PCR (qRT-PCR) were carried out using the PrimeScript ${ }^{\mathrm{TM}} 1^{\text {st }}$ Strand cDNA Synthesis Kit (Takara Bio Inc., Shiga, Japan) and RotorGene SYBR Green PCR Kit (Qiagen, Hilden, Germany), respectively. Total RNA, extracted from A549 cells using TRIzol reagent (Invitrogen), was mixed with various concentrations of synthetic miRNA21 ( 0 and $5 \mathrm{fM} ; 0.1,5,50$, and $500 \mathrm{pM} ; 5,10,50$, and $100 \mathrm{nM}$ ). The mixtures containing A549 total RNA $(1 \mu \mathrm{g})$ and various concentrations of miRNA21 were subjected to reverse transcription using the PrimeScript ${ }^{\mathrm{TM}} 1^{\text {st }}$ Strand cDNA Synthesis Kit (Takara), according to the manufacturer's instructions. qRT-PCR was performed with forward primer $(0.5 \mu \mathrm{M})$, reverse primer $(0.5 \mu \mathrm{M})$, and $2 \mu \mathrm{L}$ of cDNA in a real-time thermocycler Rotor-gene Q system (Qiagen). The reaction mixture was incubated for $5 \mathrm{~min}$ at $16^{\circ} \mathrm{C}$, followed by 45 cycles of $95^{\circ} \mathrm{C}$ for $5 \mathrm{sec}, 60^{\circ} \mathrm{C}$ for $10 \mathrm{sec}$, and $72^{\circ} \mathrm{C}$ for $1 \mathrm{sec}$. The relative intensity was evaluated and normalized to the expression of U6 snRNA (Figure S4a). The primers for miRNA21 and U6 snRNA are shown in Table S1.

\section{Specificity of RCT DNA and F-PNA in the GO-based fluorometric miRNA detection system}

To assess the specificity of the GO-based miRNA detection system, we prepared several miRNAs (miRNA21, miRNA16, miRNA31, and miRNA155). Corresponding RCT sequences 
and PNA probes with different fluorophores were designed for amplification and detection of the different miRNAs (sequences are shown in Table S1). Different fluorophores was used to label the probe PNAs: FITC $\left(\lambda_{\mathrm{ex}}=495 \mathrm{~nm}\right.$ and $\left.\lambda_{\mathrm{em}}=519 \mathrm{~nm}\right)$, ATTO550 $\left(\lambda_{\mathrm{ex}}=554 \mathrm{~nm}\right.$ and $\left.\lambda_{\mathrm{em}}=576 \mathrm{~nm}\right)$, and Cy5 $\left(\lambda_{\mathrm{ex}}=650 \mathrm{~nm}\right.$ and $\left.\lambda_{\mathrm{em}}=670 \mathrm{~nm}\right)$. The fluorophore was labeled at the 5'end of PNA21, PNA31, and PNA155, respectively. To assess the specificity of the RCT, a mixture of miRNAs (miRNA21, miRNA31, and miRNA155; $10 \mathrm{nM}$ each) was incubated with one or a mixture of RCTs (RCT21, RCT31, and RCT155; $100 \mathrm{nM}$ each) for the ligation and RCA reactions (Figure 3a). For the negative control, RCT16 (100 nM) was added to the reaction mixture containing the mixture of miRNAs without miRNA16. The ligation and RCA reactions were conducted as described in the multiwall-plate setup, as described above. The aliquot of RCAP ( $3 \mu \mathrm{L})$ was then hybridized to each of the F-PNAs (FITC-PNA21, ATTO550PNA31 and Cy5-PNA155), respectively. The specificity of the F-PNA in the GO-based miRNA detection method was also examined by using a mixture of F-PNAs containing FITCPNA21 (50 nM), ATTP550-PNA31 (50 nM), and Cy5-PNA155 (50 nM) against the respective RCAPs (Figure 3b). The RCAP21, RCAP16, RCAP31, and RCAP155 were synthesized using their corresponding pairs of RCT DNA and miRNA. One or a mixture of RCAPs (RCAP21, RCAP31, and RCAP155) was subjected to F-PNA hybridization using the mixture of F-PNAs. As a negative control, RCAP16 was added to the reaction mixture containing the mixture of FPNAs without the F-PNA16 (complementary to miRNA16). The RCAP/F-PNA hybrid reaction mixture $(15 \mu \mathrm{L})$ was then transferred to each well containing $35 \mu \mathrm{L}$ of GO solution $(5 \mu \mathrm{g} / \mathrm{mL})$, GO binding buffer, and distilled water in a 96-well plate. After incubation at $25^{\circ} \mathrm{C}$ for 20 min, the fluorescence was measured with a multilabel plate reader (Synergy MxMicroplate Reader; Biotek Instruments, Winooski, VT, USA). 


\section{Multiplexed detection in GO-based fluorometric miRNA detection}

For multiplexed detection, we prepared four F-PNA probes. The FITC fluorophore was labeled at the 5'end of the PNA16, PNA21, PNA31, and PNA155 sequences, which were complementary to miRNA16 miRNA21, miRNA31, and miRNA155, respectively. One or several miRNAs (miRNA16, miRNA21, miRNA31, and miRNA155; $10 \mathrm{nM}$ each) was mixed and ligated with its respective RCT $(100 \mathrm{nM})$. After the ligation reaction, RCA was subsequently conducted with the ligation product. Thereafter, $3 \mu \mathrm{L}$ of RCAP reaction mixture, $5 \mu \mathrm{L}$ of FITC-PNA probe $(1 \mu \mathrm{M})$, and $7 \mu \mathrm{L}$ of distilled water were mixed and incubated by first heating at $85^{\circ} \mathrm{C}$ for $3 \mathrm{~min}$ and then slowly cooling to room temperature for $15 \mathrm{~min}$. Each RCAP reaction mixture using RCT21, RCT31, or RCT155 was probed with FITC-PNA21, FITCPNA31, or FITC155, respectively, as described above. Then, $15 \mu \mathrm{L}$ of the RCAP/F-PNA hybrid reaction mixture was then transferred to each well containing $35 \mu \mathrm{L}$ of GO solution (5 $\mu \mathrm{g} / \mathrm{mL}$ ) in a 96 -well plate. After further incubation at $25^{\circ} \mathrm{C}$ for $20 \mathrm{~min}$, fluorescence images of the 96-well plate were obtained using a fluorescent imaging system (IVIS-Lumina II; Caliper Life Sciences, Hopkinton, MA, USA) (Figure 3c).

\section{Specificity of the GO-based fluorometric miRNA detection system using miRNAs containing} single base mismatches

Variants of miRNA21 containing a single-base mismatch at the binding site of the 5' or 3'end of the RCT sequence were prepared (sequences are shown in Table S1). Ligation and RCA reaction were performed using RCT21 $(100 \mathrm{nM})$ in the presence of wild type miRNA21 (10 $\mathrm{nM})$ or miRNA21 variants containing a single-base mismatch $(100 \mathrm{nM})$, as described above. As a control experiment, miRNA16 (10 nM) was used with RCT21 in the same reaction. The RCA product DNA bands were resolved in 1\% agarose gel electrophoresis and visualized with 
ethidium bromide (Figure 4a). For fluorometric detection, the RCA products were subjected to F-PNA21 $(100 \mathrm{nM})$ hybridization, and the hybrid was then mixed with GO solution $(5 \mu \mathrm{g} / \mathrm{mL})$ in a 96 -well plate, as described above. After incubation at $25^{\circ} \mathrm{C}$ for $20 \mathrm{~min}$, the fluorescence was measured with a multilabel plate reader (VICTOR X3) at an excitation wavelength of 485 $\mathrm{nm}$ and an emission wavelength of $535 \mathrm{~nm}$ (Figure 4b). 
Table S1. Oligonucleotide sequences used in the graphene oxide-based fluorometric assay.

\begin{tabular}{|c|c|}
\hline Oligonucleotide (nts) & Sequence (from 5' to 3') \\
\hline miRNA16 (22) & UAG CAG CAC GUA AAU AUU GGC G \\
\hline miRNA21 (22) & UAG CUU AUC AGA CUG AUG UUG A \\
\hline miRNA31 (21) & AGG CAA GAU GCU GGC AUA GCU \\
\hline miRNA155 (23) & UUA AUG CUA AUC GUG AUA GGG GU \\
\hline RCT16 (62) & $\begin{array}{l}\text { Phosphate - ACG TGC TGC TA T AAC GAC GAG AAA GGG CTG CCA } \\
\text { GAT ACT CTT CGC AAT TTT CGC CAA TAT TT }\end{array}$ \\
\hline RCT21 (62) & $\begin{array}{l}\text { Phosphate - CTG ATA AGC TAT AAC GAC GAG AAA GGG CTG CCA GAT } \\
\text { ACT CTT CGC AAT TTT TCA ACA TCA GT }\end{array}$ \\
\hline RCT31 (61) & $\begin{array}{l}\text { Phosphate - GCA TCT TGC CTT AAC GAC GAG AAA GGG CTG CCA } \\
\text { GAT ACT CTT CGC AAT TTT AGC TAT GCC A }\end{array}$ \\
\hline RCT155 (63) & $\begin{array}{l}\text { Phosphate - GAT TAG CAT TAA TAA CGA CGA GAA AGG GCT GCC AGA } \\
\text { TAC TCT TCG CAA TTT TAC CCC TAT CAC }\end{array}$ \\
\hline PNA16 (22) & FITC - CGC CAA TAT TTA CGT GCT GCT A \\
\hline PNA21 (22) & FITC - TCA ACA TCA GTC TGA TAA GCT A \\
\hline PNA31 (21) & $\begin{array}{l}\text { ATTO550 - AGC TAT GCC AGC ATC TTG CCT } \\
\text { FITC - AGC TAT GCC AGC ATC TTG CCT }\end{array}$ \\
\hline PNA155 (23) & $\begin{array}{l}\text { Cy5 - ACC CCT ATC ACG ATT AGC ATT AA } \\
\text { FITC - ACC CCT ATC ACG ATT AGC ATT AA }\end{array}$ \\
\hline miRNA21_G(22) & UAGCUUAUCAUACUGAUGUUGA \\
\hline miRNA21_A (22) & UAGCUUAUCAGUCUGAUGUUGA \\
\hline miR21_RT primer (44) & CTCAACTGGTGTCGTGGAGTCGGCAATTCAGTTGAGTCAACATC \\
\hline miR21_Forward primer (30) & ACACTCCAGCTGGGTAGCTTATCAGACTGA \\
\hline miR21_Reverse primer (16) & TGGTGTCGTGGAGTCG \\
\hline U6 small RNA_RT primer (20) & AAAATATGGAACGCTTCACG \\
\hline U6 small RNA_Forward primer (32) & CGCTTCGGCAGCACATATACTAAAATTGGAAC \\
\hline U6 small RNA_Reverse primer (28) & GCTTCACGAATTTGCGTGTCATCCTTGC \\
\hline
\end{tabular}


(a)

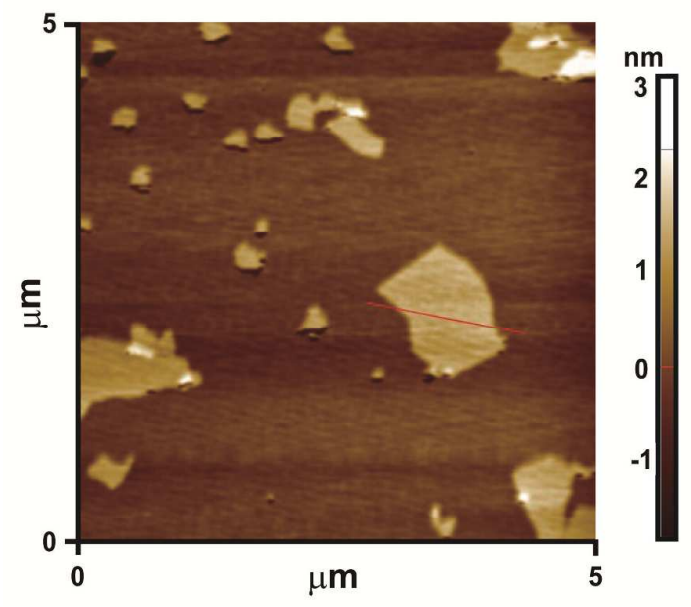

(b)

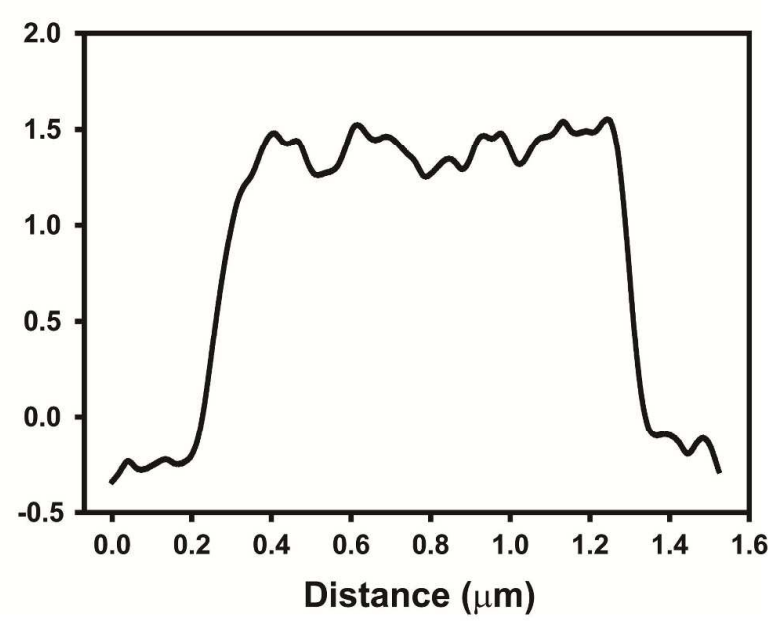

Figure S1. Atomic force microscopy (AFM) image of graphene oxide (GO) and determination of its height profile. (a) Tapping mode AFM image of GO sheets. (b) Height profile of GO. The average thickness was estimated to be $1.884 \mathrm{~nm}$ for the GO sheet, which corresponds to one atomic layer. 


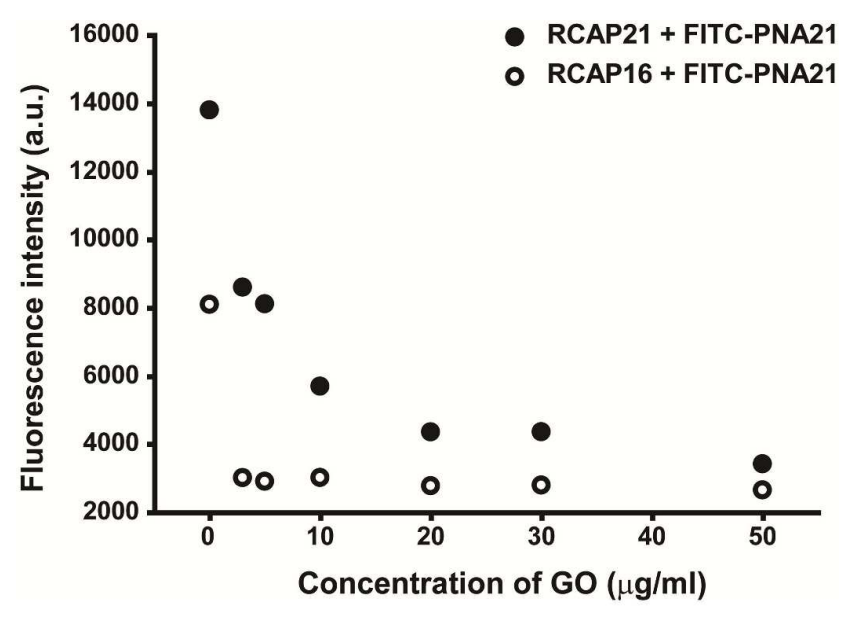

Figure S2. Optimization of the graphene oxide (GO) concentration for fluorescence-quenching. Each RCAP/F-PNA21 hybrid was mixed with increasing concentrations of GO $(0,3,5,10,20$, 30 , and $50 \mu \mathrm{g} / \mathrm{mL}$ ). Fluorescence was measured with the excitation wavelength at $485 \mathrm{~nm}$ and the emission wavelength at $535 \mathrm{~nm}$, using a multilabel plate reader. 
(a)

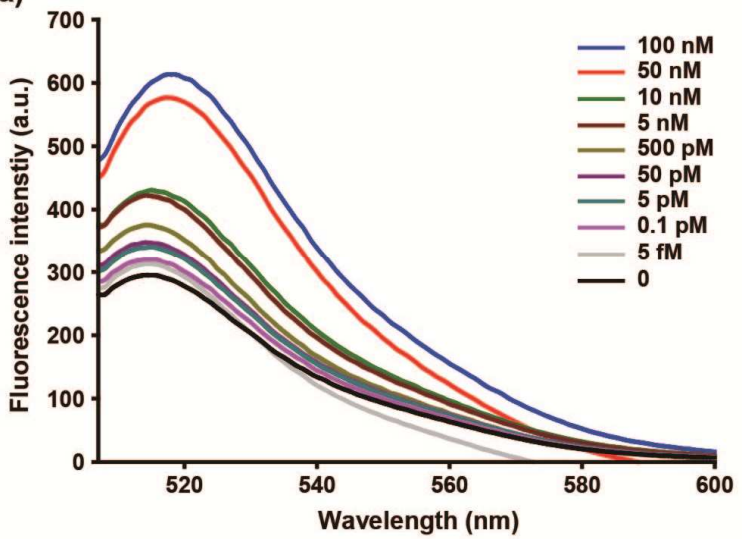

(b)

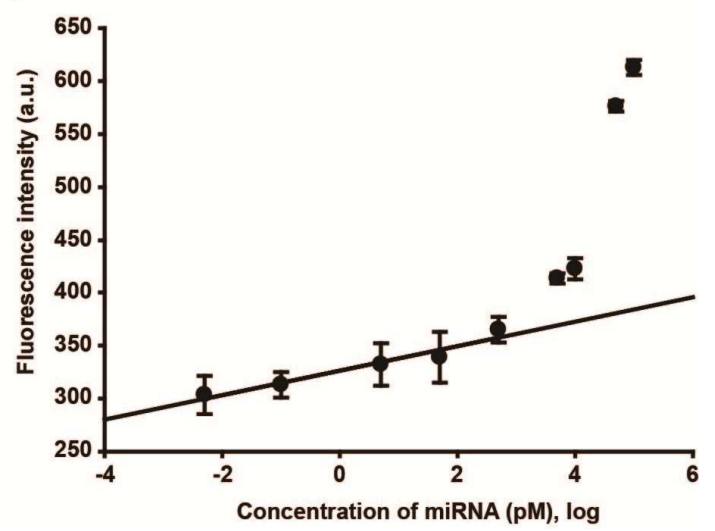

Figure S3. Detection of miRNA21 present in a cellular RNA sample. (a) The fluorescence emission spectrum $\left(\lambda_{\mathrm{ex}}=495 \mathrm{~nm}\right)$ of F-PNA21 in the RCAP21/F-PNA21 hybrid upon addition of miRNA21 at different concentrations $(0-100 \mathrm{nM})$ to the total cellular RNA (1 $\mu \mathrm{g})$. (b) The linear relationship (solid line) between the fluorescence intensity and the logarithm of target miRNA concentrations in the range from $5 \mathrm{fM}$ to500 pM. Error bars reflect three separate measurements. 
(a)
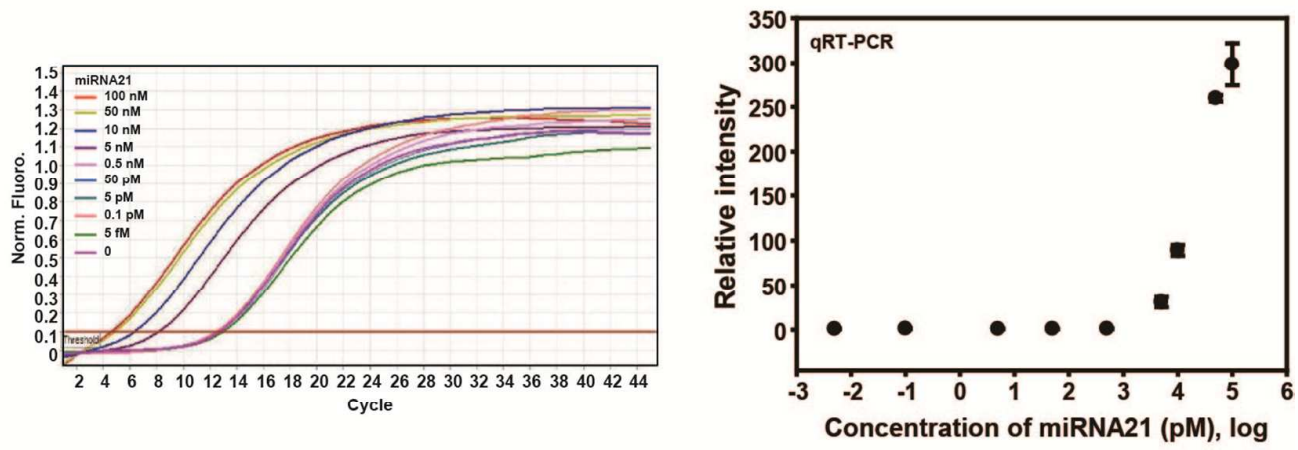

(b)

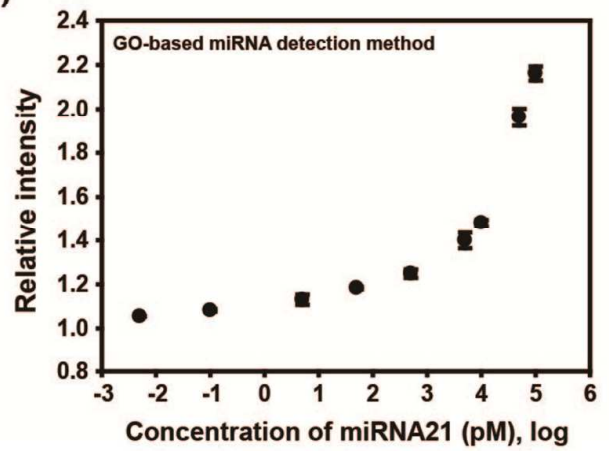

(c)

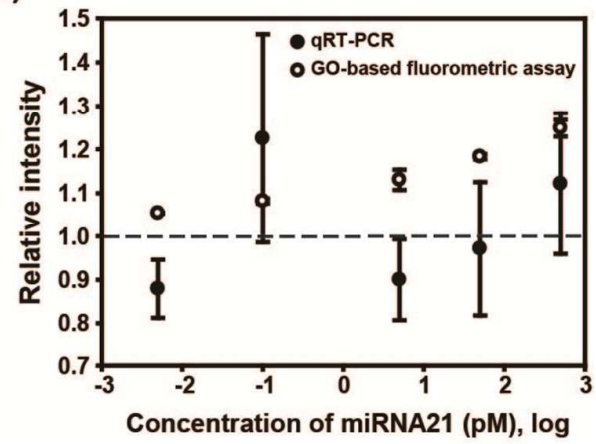

Figure S4. Comparison of two methods for miRNA detection: quantitative real-time PCR (qRT-PCR) and the graphene oxide (GO)-based fluorometric assay.Various concentrations (0$100 \mathrm{nM}$ ) of miRNA were spiked in total cellular RNA (1 $\mu \mathrm{g})$. (a) qRT-PCR; the relative intensity was evaluated and normalized to the expression of U6 small nuclear RNA (U6 snRNA). The relative intensity increase with an increasing concentration of miRNA21 was plotted against logarithmic concentrations of miRNA. (b) GO-based miRNA fluorometric detection. The relative fluorescence intensity was increased as the concentration of miRNA21 was increased. (c) The fluorescence intensity in the absence of miRNA21 was normalized, and the relative signal intensity in the presence of miRNA21 was plotted against logarithmic miRNA concentrations. The relative signal intensities of the two methods were plotted against the logarithm of low concentrations of miRNA21 (from $5 \mathrm{fM}$ to $500 \mathrm{pM}$ ). A steady increase in relative signal intensity was observed with the GO-based miRNA fluorometric assay, whereas scattered signal intensities were observed with qRT-PCR at low concentrations of miRNA. 


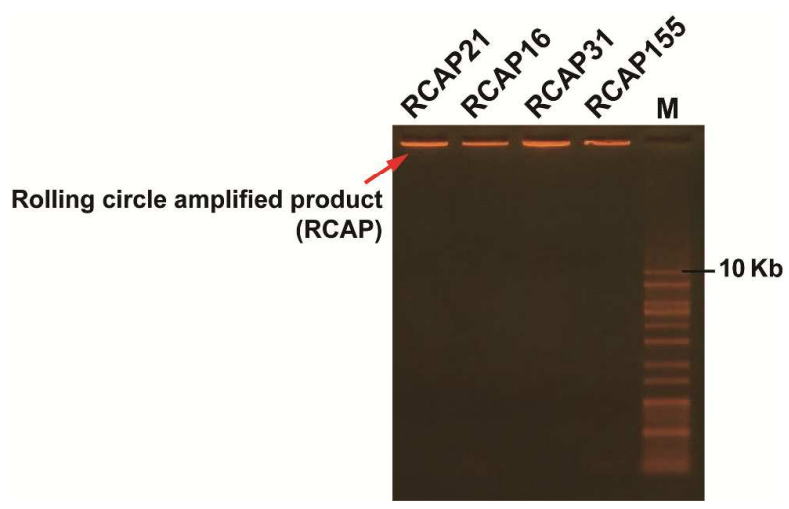

Figure S5. Gel electrophoresis analysis of the rolling circle-amplified product (RCAP) obtained from each corresponding pair of miRNA and RCT DNA. RCAP DNA bands representing long stretches of single-stranded DNA were resolved by $1 \%$ agarose gel electrophoresis and visualized by ethidium bromide staining under UV transillumination. 


\section{References}

(1) Chen,C.;Ridzon,D. A.;Broomer,A. J.;Zhou,Z.;Lee,D. H.;Nguyen,J. T.;Barbisin,M.;Xu,N. L.;Mahuvakar,V. R.;Andersen,M. R.;Lao,K. Q.;Livak,K. J.;Guegler,K. J. Nucleic Acids Res.2005, 33, e179. 